\title{
Take the Initiative, Stop Being Passive to NCDs: A PCA-Weighted Composite Indicator towards Prevalence of NCDs in Malaysia
}

\author{
Grace Chee Yao Lee \\ Faculty of Economics and Business, Universiti Malaysia Sarawak \\ 94300 Kota Samarahan, Sarawak, Malaysia \\ Shirly Siew-Ling Wong \\ Faculty of Economics and Business, Universiti Malaysia Sarawak \\ 94300 Kota Samarahan, Sarawak, Malaysia \\ Chin-Hong Puah \\ Faculty of Economics and Business, Universiti Malaysia Sarawak \\ 94300 Kota Samarahan, Sarawak, Malaysia
}

Received: May 16, 2021 Accepted: June 12, 2021 Published: June 17, 2021

doi:10.5296/ber.v11i3.18647～URL: https://doi.org/10.5296/ber.v11i3.18647

\begin{abstract}
In today's highly dynamic socio-economic environment, the high degree of non-communicable diseases (NCDs) poses both direct and indirect health problems for nations. This study constructed a composite Non-Communicable Diseases Risk Indicator (NCDRI) that comprises leading characteristics to predict the movement of NCDs' prevalence, which serves as an early signaling tool for policymakers and public health sectors. A weighting scheme for both non-weighted and principal component analysis (PCA)-weighted was applied from the PCA loading factor. The findings verified that the constructed PCA-weighted approach had a remarkable lead time, which also produced better lead times and was consistent in predicting the direction of change in the fluctuations caused by NCDs' prevalence. An appropriate regime for policymaking and implementation is required, followed by periodic monitoring and rapid action, to reduce the deadly diseases.
\end{abstract}


The findings of this study demonstrate that the cost indicator marked the most significant risk factor to indicate the prevalence of NCDs; therefore, policymakers should converge on this indicator so that cost-effective interventions can result in more valuable outcomes.

Keywords: Non-communicable diseases, Risks, Composite indicator, PCA-weighted

\section{Introduction}

Non-communicable diseases (NCDs) are defined as chronic diseases that tend to have a long diagnosis and are the result of a combination of genetic, physiological, environmental, and behavioral factors. These diseases occur among all ages, genders, regions, and countries. Contrary to popular opinion, the data indicate that almost half of the disease burden that strikes the world's low- and middle-income countries hardest consists of NCDs (WHO, 2017). Malaysia's Ministry of Health (MOH) and the World Health Organization (WHO) have reported that, due to absenteeism, presenteeism in the workplace, and the premature death of the working age population, Malaysia's gross domestic product (GDP) has experienced annual losses of upwards of RM8.91 billion, which is equivalent to about 0.65 percent of Malaysia's GDP. More specifically, the MOH and WHO also reported that NCDs placed a significant health burden on countries resulting from disability and loss of healthy life years, called the burden of disease costs. This "indefinable" cost is estimated to be around RM100.79 billion yearly, which is equivalent to 7.35 percent of Malaysia's GDP. This situation shows that NCDs hamper the social and economic development of the country.

In addition, limited research has been conducted in developing countries due to inadequate resources for gathering the information and validating the collective information. The lack of data sources in supporting the research on NCDs is a major issue. Effective solutions and policies are always associated with reliable information, data, and steadfast evidence. Cost-effective interventions can result in higher and more valuable outcomes for public health. Despite more awareness campaigns being conducted, the rate of NCDs has not be reduced. Health awareness programs are becoming a well-established practice around the world, yet people remain a key vulnerability, and the data do not match the outcomes of these awareness programs. People acquire the relevant healthcare knowledge but maintain their same unhealthy lifestyles and practices. Hence, action is required to target the use of composite indicators in NCD surveillance in Malaysia.

To understand the facts, this study reviewed the indicator construction process. The most prominent example of this type of work was carried out by Burns and Mitchell (1946), whose early emphasis on the consistent pattern of movement among different variables over the movement cycle led to the creation of composite leading, coincident, and lagging indexes. By adopting and adapting Burns and Mitchell's (1946) work, the indicator construction process becomes a very effective method when used in indicator analysis. Furthermore, a weighting scheme, adopted from principal component analysis (PCA), is applied to the constructed Non-Communicable Diseases Risk Indicator (NCDRI), and the directional accuracy is tested to examine if the indicator holds a forecasting ability. 


\section{Methodology}

In line with the WHO's initiative to combat the NCD epidemic, the present study aims to develop a country-level NCD monitoring and tracking framework to provide a clearer picture of how the risk for NCDs changes in Malaysia. To achieve this aim, this study identified six pillars namely, behavior risk, morbidity, mortality, cost indicators, determinants of health, and health system response based on the WHO's global monitoring framework as well as the NCDs' causation pathway. The sub-components making up each individual pillar will be recognized following the ideology of indicator construction proposed by the Conference Board (2000).

Each pillar will be assigned a weight to reflect its relative significance toward the evolvement of the prevalence of NCDs in Malaysia. Table 1 summarizes the framework of the NCDRI development adopted in the present study. After selecting the component series and reference series, the study proceeded with the construction of a composite indicator (i.e., the NCDRI), which involved selecting a set of appropriate representative series. Cycle extraction and detrending procedures were subsequently carried out using the Christiano-Fitzgerald (CF) filter developed by Christiano and Fitzgerald (2003). The turning points were determined using Bry and Boschan's (1971) technique to analyze the movement of the cycle turns, particularly the peaks and troughs. A weighting scheme for equal-weighted and PCA-weighted sub-pillars and sub-components was applied. The constructed NCDRI and the directional accuracy test was carried out to determine the indicator's forecasting ability.

Table 1. Framework of Non-Communicable Diseases Risk Indicator (NCDRI)

\begin{tabular}{|l|l|}
\hline Non-Communicable Diseases Risk Indicator (NCDRI) \\
\hline Pillars & Sub-component(s) \\
\hline Behaviour Risk Indicator & $\begin{array}{l}\text { Tobacco, Smoking, Drug Use, Alcoholic Beverages, Dietary Risks, Low } \\
\text { Physical Activity }\end{array}$ \\
\hline Morbidity Indicator & $\begin{array}{l}\text { Prevalence of Stroke, Prevalence of Obesity, Prevalence of Diabetes } \\
\text { Mellitus, Prevalence of Overweight, Prevalence of Cancers }\end{array}$ \\
\hline Mortality Indicator & $\begin{array}{l}\text { Perinatal Mortality Rate, Neonatal Mortality Rate, Infant Mortality Rate, } \\
\text { Toddler Mortality Rate, Maternal Mortality Rate }\end{array}$ \\
\hline Cost Indicators Indicator & Consumer Price Index on Healthcare \\
\hline $\begin{array}{l}\text { Determinants of } \\
\text { Health Indicator }\end{array}$ & Education, Gender, Income Level, Prevalence of Undernourishment \\
\hline $\begin{array}{l}\text { Health System } \\
\text { Response Indicator }\end{array}$ & $\begin{array}{l}\text { Health System Capacity, Expenditure on Health Per Capita, Total Number of } \\
\text { Beds, Total Number of Hospitals, Coverage of 7 Vaccines, Family with } \\
\text { Modern Contraception, Coverage on Essential Service Index }\end{array}$ \\
\hline
\end{tabular}

\section{Empirical Findings and Discussion}

\subsection{Weighting Scheme on PCA-Weighted NCDRI}

To identify the weighting scheme of the weighted NCDRI, PCA was adopted to determine the pillars and their sub-components optimal weight (see Figure 1). These weighting schemes were used to develop a novel PCA-weighted NCDRI. Specifically, a two-stage PCA weighting scheme was applied to both pillars and sub-components. Figure 1 summarizes the 
weights assigned on each pillar that makes up the newly constructed NCDRI.

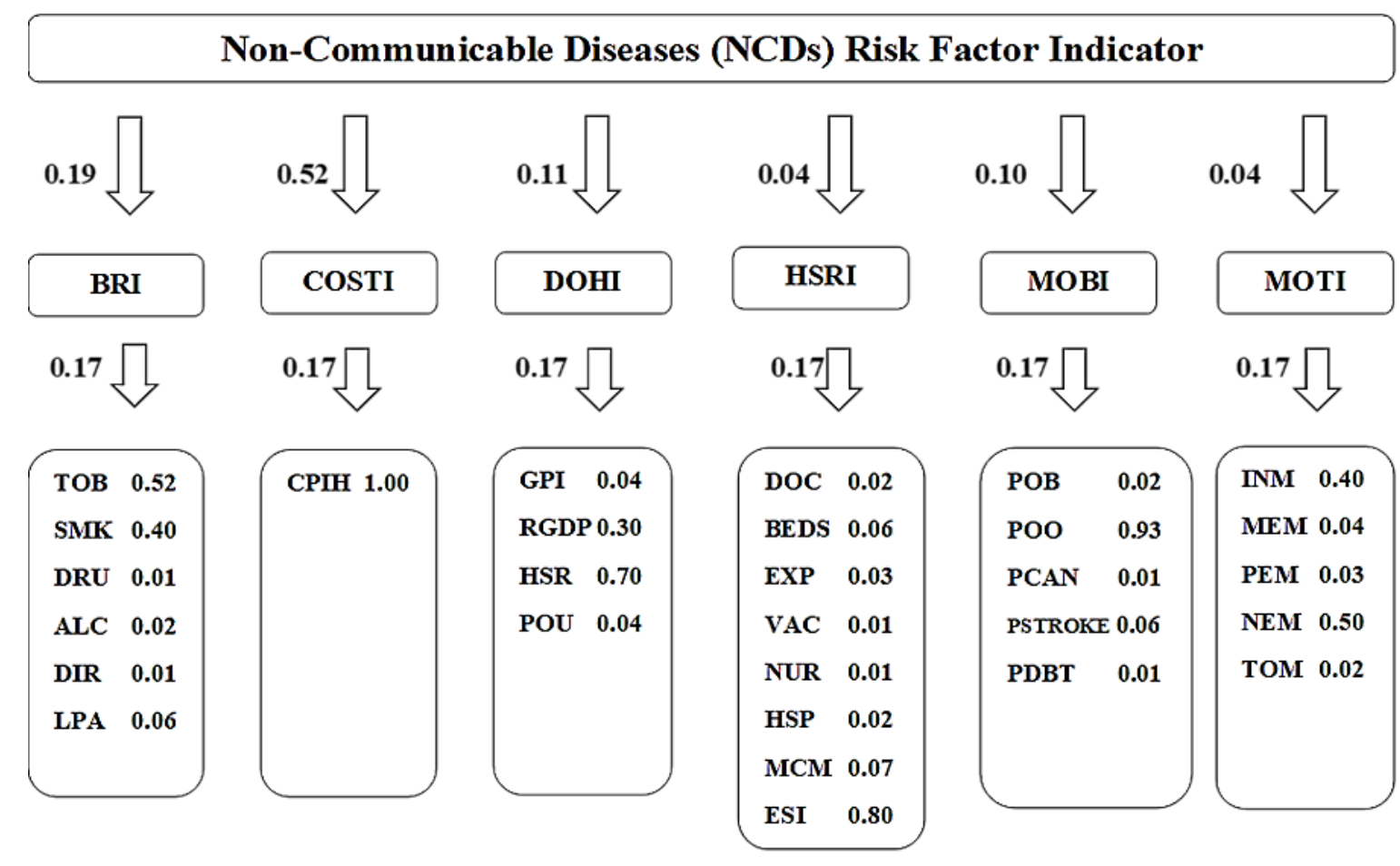

Figure 1. Weighting Scheme on PCA-weighted, NCDRI

\subsection{Cyclical Movement of the Reference Series and Constructed NCDRI}

In developing nations, the NCD epidemic is typically monitored via the total number of deaths from NCDs, the mortality rate due to NCDs, and the incidence of NCDs reported by the $\mathrm{MOH}$ and/or the WHO. Thus far, the prevalence of NCDs is the best available statistic reflecting the trend in risk for NCDs in Malaysia as it describes the number of individuals at risk of contracting NCDs. In other words, the prevalence of NCDs reflects the proportion of a particular population affected by NCDs. Hence, in this study, the total prevalence of NCDs (NCDPRE) was selected as the reference point for reproducing the cyclical movement of NCDs in Malaysia and serves as the benchmark series for comparing the two constructed risk indicators: equal-weighted and PCA-weighted NCDs.

To further clarify the results, the equal-weighted (NCDIE) and the PCA-weighted (NCDRI) NCDs are graphically represented in Figure 2, which dated the turning points using Bry and Boschan's (1971) technique. As shown in this figure, a weighted indicator may better reflect the relative contribution of the component series toward the reference series, which is represented by NCDPRE. Indeed, the PCA-weighted NCDRI has a better leading power than the equal-weighted NCDIE based on the cyclical movement analysis. As shown, the PCA-weighted NCDRI moves ahead of NCDIE most of the time. Hence, the PCA-weighted NCDRI can be used to track most of the important episodes in the prevalence of NCDs. Finally, the weights imposed on the sub-components do not deteriorate the signaling ability, 


\section{I Macrothink}

but rather ameliorate the capability.
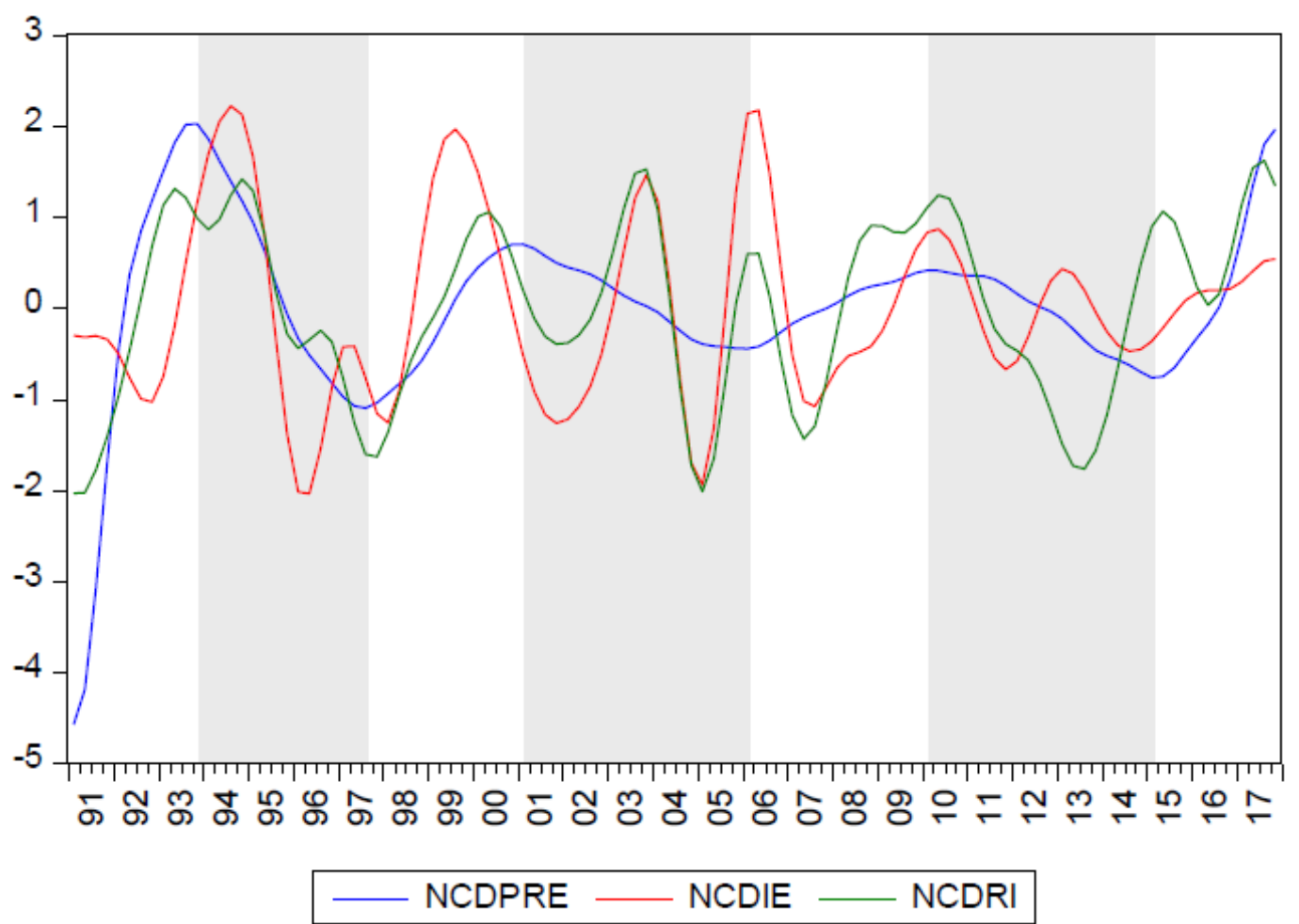

Figure 2. Cyclical Movement Comparison between NCDPRE, NCDIE and NCDRI

\subsection{Turning Point Analysis of Constructed NCDRI}

The results of the turning point analysis generated from Bry and Boschan's (1971) algorithm are shown in Table 2. NCDRI showed the most leading power of the two constructed indicators, with a lead of on average 3.8 quarters against the reference series. NCDRI was found to track most of the historical turning points across the sample period with the correct timing. Moreover, this finding suggests that the constructed PCA-weighted NCDRI, in which a weighting scheme was applied to both the sub-pillars and sub-components, had an intrinsic leading ability that enabled the indicator to predict the significant turning points in the prevalence of NCDs in Malaysia with more advanced timing.

Table 2. Turning Point Analysis of NCDPRE, NCDIE and LNCDRI

\begin{tabular}{|c|c|c|c|c|}
\hline & NCDPRE & NCDIE & NCDRI & Reasons of NCDs Risks Reduction \\
\hline Peak & 1993Q4 & 1994Q3 & 1993Q2 & \multirow{2}{*}{$\begin{array}{l}\text { Control of Tobacco Products } \\
\text { Regulations }\end{array}$} \\
\hline Trough & 1997Q3 & 1996Q2 & 1997Q4 & \\
\hline Peak & 2001Q1 & 1999Q3 & 2000Q2 & \multirow[t]{2}{*}{ Wellness Policy } \\
\hline Trough & 2006Q1 & 2005Q1 & 2005Q1 & \\
\hline Peak & 2010Q1 & 2010Q2 & $2008 \mathrm{Q} 4$ & \multirow[t]{2}{*}{ National Plan of Action on Nutrition } \\
\hline Trough & $2015 \mathrm{Q} 1$ & 2014Q3 & 2013Q3 & \\
\hline Average of Lead/Lag (Quarters) & & 2.2 & 3.8 & \\
\hline
\end{tabular}




\subsection{Directional Accuracy Test}

After constructing the equal-weighted (NCDIE) and PCA-weighted (NCDRI) NCD risk indicators and reference series, directional accuracy and binomial tests were performed. For comparison purposes, Table 3 shows the differences in the predictive power between the equal-weighted and PCA-weighted NCD risk indicators.

Table 3. Comparative Analysis of Indicators' Directional Accuracy

\begin{tabular}{|l|l|l|l|l|}
\hline & \multicolumn{2}{|l|}{ Directional Accuracy } & \multicolumn{2}{l|}{ P (Binomial) } \\
\hline & NCDIE & NCDRI & NCDIE & NCDRI \\
\hline Lag 1 & $57.84 \%$ & $73.53 \%$ & $0.023^{* *}$ & $0.000^{* * *}$ \\
\hline Lag 2 & $57.43 \%$ & $73.27 \%$ & $0.026^{* *}$ & $0.000^{* * *}$ \\
\hline Lag 3 & $57.00 \%$ & $73.00 \%$ & $0.030^{* *}$ & $0.000^{* * *}$ \\
\hline Lag 4 & $56.57 \%$ & $72.73 \%$ & $0.034^{* *}$ & $0.000^{* * *}$ \\
\hline
\end{tabular}

Note: Asterisks $* *$ and $* * *$ denote significant at $5 \%$ and $1 \%$ levels, respectively.

In this case, the rate of directional accuracy presents important interpretations regarding the predictive power of the constructed NCD risk indicators. First, the constructed PCA-weighted NCDRI was found to be more leading and consistent in predicting the direction of change in the fluctuations causing the prevalence of NCDs. In particular, the rate of directional accuracy improved from 57 percent to 73 percent when using NCDRI. In general, the two constructed NCD risk indicators in Table 3 depict decent directional accuracy, where all lags are greater than 50 percent; as this result demonstrates, the risk indicators predicted the direction of change in prevalence of NCDs with good predictive power. However, when comparing the directional accuracy rate for the equal-weighted NCDIE and the PCA-weighted NCDRI, predicting the direction of the movement of NCDPRE showed major improvement. The weighting scheme for the sub-pillars and sub-components contributed to enhancing the directional accuracy of the constructed NCDRI.

\section{Conclusion and Implications}

Establishing a set of weighting schemes using PCA by assigning an appropriate weight for each of pillar and component is important. The PCA-weighted approach is applicable for constructing NCD risk indicators and could be even more persuasive in different kinds of studies. A number of indicator studies have been carried out by adopting composite leading indicators. For example, Kueh et al. (2021) constructed a financial vulnerability indicator in China's financial market for use as a barometer for the state of financial vulnerability. Puah et al. (2016) used their composite indicator to predict the housing market dynamics in Malaysia. Almost et al. (2018) constructed leading indicators and used their findings as a guideline for healthcare organizations seeking to prioritize occupational health and safety management systems. With the aid of the indicators, health and safety outcomes could be improved and strengthened. The empirical findings of the current study demonstrated that the PCA-weighted indicator (NCDRI) could track significant events affecting the prevalence of NCDs in Malaysia with better predictive power than the equal-weighted indicator. In terms of practical aspects, policymakers should have sufficient budgets and effective budget allocation 
to address the prevalence of NCDs with the contribution of a weighting scheme. A precise budget for specific aspects will help concentrate resources to improve clarity and focus on the essential aspects.

An appropriate regime for policymaking and implementation is required, followed by periodic monitoring and rapid actions, to reduce non-communicable diseases. The findings of this study suggest that the cost indicator is the most significant risk factor for indicating the prevalence of NCDs; therefore, policymakers should focus more on this indicator. The Consumer Price Index (CPI) for Healthcare, a measure of medical expenses in households, includes medical products, healthcare appliances, and equipment. Based on statistics from the World Bank, the CPI of Healthcare has experienced a tremendous increase since 1990. Patients continue to bear high medical costs year after year. Malaysia's healthcare system is currently supported by both the government sector and the private sector. As the government has sought to improve healthcare facilities and infrastructure, the unprecedented growth of private healthcare services has posed serious challenges to both consumers and policymakers. To obtain prompt and efficient healthcare services, patients tend to shift to the private sector, but this action increases the patients' expenses more than if they choose government services.

\section{Acknowledgments}

The authors acknowledge the financial support of the Universiti Malaysia Sarawak and Transdisciplinary Research Scheme (TRGS) No. F01/TRGS/1521/2016. Any flaws are the responsibility of the authors.

\section{References}

Almost, J. M., VanDenKerkhof, E. G., Strahlendorf, P., Tett, L. C., Noonan, J., Hayes, T., \& E Silva, V. S. (2018). A study of leading indicators for occupational health and safety management systems in healthcare. BMC Health Services Research, 18(1), 296. https://doi.org/10.1186/s12913-018-3103-0

Bry, G., \& Boschan, C. (1971). Programmed selection of cyclical turning points. In Cyclical Analysis of Time Series: Selected Procedures and Computer Programs. NBER. pp. 7-63.

Burns, A. F., \& Mitchell, W. C. (1946). Measuring Business Cycles, NBER, Studies in Business Cycle.

CodeBlue News. (2020). Cardiovascular Diseases, Diabetes, Cancer Cost Malaysia RM9 Bil Yearly in Productivity Loss: $\mathrm{MOH}, \mathrm{WHO}$. [Online] Available:

https://codeblue.galencentre.org/2020/09/08/cardiovascular-diseases-diabetes-cancer-cost-ma laysia-rm9-bil-yearly-in-productivity-loss-moh-who/

Christiano, L. J., \& Fitzgerald, T. J. (2003). The band pass filter. International Economic Review, 44(2), 435-465. https://doi.org/10.1111/1468-2354.t01-1-00076

Dickey, D. A., \& Fuller, W. A. (1981). Likelihood ratio statistics for autoregressive time series with a unit root. Econometrica: Journal of the Econometric Society, 49(4), 1057-1072. https://doi.org/10.2307/1912517 
Filardo, A. J. (1994). Business Cycle Phases and Their Transitional Dynamics. Journal of Business and Economic Statistics, 12(3), 299-308. https://doi.org/10.2307/1392086

Freudenberg, M. (2003). Composite indicators of country performance: a critical assessment. https://doi.org/10.1787/405566708255

Kuek, T.-H., Puah, C.-H., Arip, M. A., \& Habibullah, M. S. (2021). Macroeconomic perspective on constructing financial vulnerability indicator in China. Journal of Business Economics and Management, 22(1), 181-196. https://doi.org/10.3846/jbem.2020.13220

Ministry Healthcare Malaysia. (2006). Laws of Malaysia Act 586 Private Healthcare Facilities and Services Act 1998. Director, May. [Online] Available:

http://www.mma.org.my/Portals/0/privatehealthcarefacilitiesandservicesact1998.pdf

Puah, C. H., Kuek, T. H., Arip, M. A., \& Wong, S. S. L. (2016), Forecasting property market dynamics: Insights from the property cycle indicator. International Information Institute, 19(6B), 2225-2232.

World Health Organization. (2013). Non-communicable diseases and mental health (Global Action Plan for the Prevention and Control of NCDs 2013-2020). [Online] Available:

http://www.who.int/nmh/events/ncd_action_plan/en/

World Health Organization. (2021). Cancer. [Fact sheet]. [Online] Available:

http://www.who.int/en/news-room/fact-sheets/detail/cancer

World Health Organization. (2021). Non-communicable diseases. [Fact sheet]. [Online] Available: http://www.who.int/mediacentre/factsheets/fs355/en/

\section{Copyright Disclaimer}

Copyright for this article is retained by the author(s), with first publication rights granted to the journal.

This is an open-access article distributed under the terms and conditions of the Creative Commons Attribution license (http://creativecommons.org/licenses/by/4.0/). 